\title{
An Editor retires
}

Bernard Valman retires this month as editor of the Archives of Disease of Childhood after serving the journal for 12 years. He originally joined Roy Meadow as coeditor in 1982 and for the past seven years he has been senior editor. Let us subject our retiring editor to some audit. One measure of the success of a scientific journal is whether researchers want their papers published in it. We receive over 900 original scientific articles each year, an increase of $20 \%$ during the past decade and the acceptance rate has remained constant at around $30 \%$. The total number of papers published, including review articles, has increased from 300 to 400 and the circulation of the journal has increased by about $16 \%$.

Bernard has steered the journal through many changes, perhaps the most important being the introduction of the Fetal and Neonatal editions in 1988 . These were originally published quarterly and more recently bimonthly to meet an increasing demand created by the large number of high quality papers being received. Certain areas of the journal which were previously underrepresented; particularly community paediatrics and child psychiatry, have now been considerably strengthened.

During the past decade the total number of review articles published each year has doubled to about 100 . He recognised the need for review articles to contain accurate, 'state of the art' material if they were to inform readers reliably. Consequently most of these articles are now peer reviewed. He broadened the scope of the review articles by commissioning manuscripts under occasional headings such as 'Personal View' and 'Controversy' which have proved very popular. An increasing number of controversial original papers now have an accompanying commentary.

The change to the larger A4 size format of the journal upset a few readers who had paediatric size letter boxes. The blank areas on pages where consecutive articles did not 'run on' appeared even larger and this also caused some concern. Not being a gifted carpenter the letter box problem defeated Bernard, but he did solve the blank pages by arranging for a mystery person - Archivist - to write some provocative pieces as 'fillers'. When a friend disingenuously remarked of the Archives 'I only get it for the Archivist' Bernard promptly arranged for the Archivist sections to be indexed.

The other side of Bernard's professional life has been very demanding partly because he's one of those sensible paediatricians with whom one can share a difficult clinical problem and

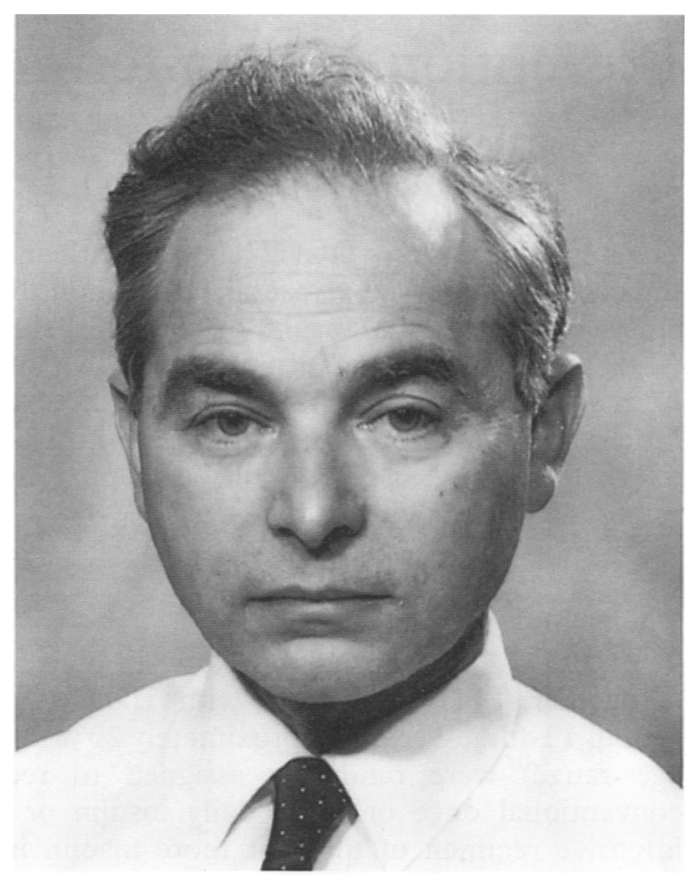

come away feeling a lot wiser. His commitment to the profession is shown through his offices such as Chairman of the Examining Board for the Diploma in Child Health, Examiner for Membership of the Royal College of Physicians, and Secretary of its Paediatric Committee, and more recently what can only be described as the ultimate act of professional commitment - Clinical Director of the Family Services and Children Services Directorate at Northwick Park Hospital.

He has made many important contributions to paediatric research especially in the fields of nutrition and feeding, infection, and neonatal care. He has that gift of recognising and exploring research opportunities when curious clinical situations present themselves. During his work as editor he has continued to write, characteristically making complicated material easy to understand and enjoyable to read. The popularity of his books such as The First Year of Life, ABC of One to Seven, and Practical Management of the Newborn is not surprising.

Throughout his years as editor he has successfully maintained an appropriate balance between the need for editorial freedom, and allegiance to the journal's professional body, the British Paediatric Association, and its publishers the British Medical Association. We thank Bernard for his 12 years of dedication to the journal and we wish him all good fortune in his social and professional life.

MALCOLM CHISWICK 